\title{
Interactive comment on "A quasi-annual record of time-transgressive esker formation: implications for ice sheet reconstruction and subglacial hydrology" by Stephen J. Livingstone et al.
}

Anna L.C. Hughes (Referee)

anna.I.c.hughes@manchester.ac.uk

Received and published: 2 April 2020

Note for Editor: I queried with the Editor before taking on this review the rules relating to Conflict of Interest. The Editor advised my review was still desired. After reading the paper I am minded to reiterate at the outset of this review that I am currently collaborating with some of the authors on an ERC-funded project - PalGlac. I note that this project is listed in the acknowledgements to the paper under review.

This paper presents new mapping of esker-bead chains in central Nunavut, Canada identified using the high-resolution ArcticDEM dataset. Consistent with previous research, the authors found the beads to be associated with De Geer moraines. Based 
on this association and the fact that De Geer moraines have an annual deposition cycle the authors reconstruct the rate of ice-margin retreat for this sector of the Laurentide Ice Sheet. Such precise quantitative information is relatively rare. A previous reviewer states that the finding that esker-bead chains have a regular deposition phasing is not new. This literature is cited by the authors. Nevertheless, the paper remains important as supports the previous findings in a new geographic location, thus confirming the regular phasing of these landforms and role to provide information on rates of retreat where they are found, when De Geer moraines may be absent. Figure 5 is excellent in this regard.

I found the paper to be well written and a pleasure to read. The description of the mapping methods and results are comprehensive and clear. Figures are high quality, although see comments below.

Figure 2/7: There is a lot of colour on A in these figures - which I appreciate, but I wonder if the figures have been checked for colour-blindness suitability. Some of the dots to indicate area $(A)$ are overlapping, I wonder if these could have been displayed as relative size empty circles to account for this? Without testing, this may or may not improve things.

Figure 8. There is a lot of information in this figure and it took me some time to understand. As for figure 2 and 7 the colour choice needs checking. For B the bin size of $5 \mathrm{~km}$ seems quite high considering most esker beads are $<1 \mathrm{~km}$ apart. Although this would likely not change the conclusion that similarly-spaced beads are associated with the same retreating margin transverse to the orientation of the chains.

Line-by-line comments:

95: practice 310: These appear to be reasonable (if relatively fast) retreat rates for a marine-terminating margin. Suggest that a citation is added here to make comparison to other former retreat rates in similar glaciological settings (either modern or palaeo). 343: suggest insert - 'that spacing of subglacial channelised...' 361: add - 'accepting

Printer-friendly version

Discussion paper 
this interpretation' or similar to caveat this statement

I would recommend acceptance of the paper as is.

TCD

Interactive comment on The Cryosphere Discuss., https://doi.org/10.5194/tc-2019-273, 2019.

Interactive

comment

Printer-friendly version

Discussion paper 